\title{
Paul B. Myrdal, Ph.D. (June 25, 1967-May 19, 2018)
}

\author{
Robert O. (Bill) Williams III ${ }^{1,2}$
}

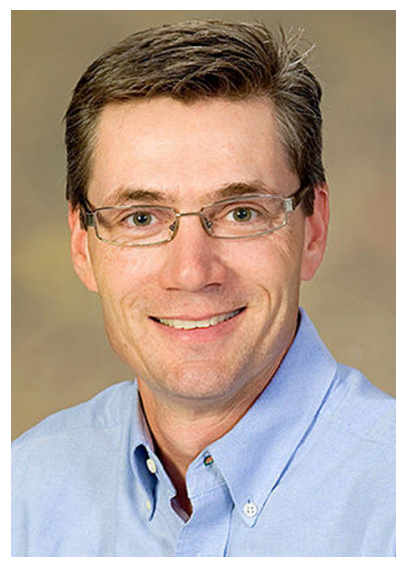

It is with great sorrow that I write you today to say that Paul B. Myrdal, Ph.D., has passed away after a courageous battle with colon cancer. I am so fortunate to have known Paul since his early days at Minnesota Mining and Manufacturing Corporation where he worked as a pharmaceutical scientist in the Drug Delivery Systems Division. He returned to the university he loved, the University of Arizona, where he continued his career in academia working with his mentor Samuel Yalkowsky, Ph.D. Paul contributed more than 80 papers to the field, including important contributions to pulmonary drug delivery. He loved to serve our AAPS and pharmaceutical sciences community, and he did this in ways that greatly advanced the pharmaceutical sciences, including service on the editorial board of Drug Development and Industrial Pharmacy and as Editor of

\footnotetext{
${ }_{1}^{1}$ Johnson \& Johnson, Molecular Pharmaceutics and Drug Delivery, Austin, Texas, USA.

${ }^{2}$ To whom correspondence should be addressed. (e-mail: Bill.Williams@austin.utexas.edu)
}

AAPS PharmSciTech. In addition, he served as co-guest editor of a highly successful theme issue dedicated to pulmonary drug delivery in AAPS PharmSciTech. He served willingly, ably, and without hesitation to AAPS, always giving his full attention to promote the journal, AAPS, and the pharmaceutical sciences. Paul was very active in AAPS, serving as Committee Member of Pharm and Drug Delivery Section, Biotechnology Section, and the Inhalation Technology Focus Group. He also served as the Faculty Advisor for the University of Arizona Student Chapter. Paul was proud to contribute to the training, education, and well-being of graduate students throughout his career, and I often met him at the annual meetings perusing posters and quizzing graduate students about their research. Paul leaves behind his loving wife, Kelly, and two children, Hunter and Caitlyn.

Thank you, Paul, for being such a fine friend, colleague, and scientist. You will be sorely missed.

Memorial donations to support mentored research projects for pharmacy students and Ph.D. candidates can be made at the American Foundation for Pharmaceutical Education (AFPE) webpage: afpepharm.org (click on the Dr. Paul B. Myrdal Memorial Fund for Pharmaceutical Education in the top right portion of the webpage) or by using the link below.

http://afpepharm.org/index.php/dr-paul-b-myrdal-memorial-fund-for-pharmaceutical-education/

Robert O. (Bill) Williams III, Ph.D.

Johnson \& Johnson Centennial Chair and Professor

Division Head, Molecular Pharmaceutics and Drug

Delivery

Editor-in-Chief, AAPS PharmSciTech 